\title{
12
}

\section{Towards a pedagogy of hybridity, reconciliation and justice}

\author{
Nico Koopman
}

\section{Introduction}

or the past decade Dr Xolile Simon and I have been teaching a course on reconciliation and justice at the University of Stellenbosch in South Africa. Our fifth year Masters of Divinity (MDiv) class is constituted by students of a wide range of ethnic, cultural and socio-economic backgrounds, as well as diversity with regard to gender and sexual orientation. Their diversity reflects the diversity of broader South African society, and of various countries in different parts of the globe. They are the students who now study together on a campus that is on a journey from exclusion to inclusion, from participation in apartheid injustices to the building of a just and reconciled society. They are part of a campus that strives to nurture hope on the continent of Africa by contributing to a life of dignity, justice and freedom on our campus and in broader society.

These students originate from communities that still experience high levels of ethnic alienation. Even though apartheid laws were scrapped two decades ago, and although there is more inter-ethnic contact and exposure than during apartheid, millions of South Africans, many struggling economically, are still insulated from each other to a great extent. These students come from different socio-economic backgrounds. The majority of our coloured and black students still struggle to survive financially, while most of white students experience socio-economic wellbeing.

The diversity of our students is also reflected in their gender composition and in their views about gender justice. They are products of a society where 
misogyny is still present to varying degrees, especially in subtle forms. Our students also have different sexual orientations and views about sexual orientation. They were exposed to crude and also subtle forms of homophobia from childhood. The diversity of our students is also perceived in terms of categories like ability and disability, age and nationality. There are often exchange students from Europe and Northern America in this class.

This diversity of students raises challenging questions that require a plurality of responses. Some of the students' questions seek for a constructive way to deal with the past:

Can't we forget the past and just go on? Why do some want to forget the past as if it is not important? Can't we do away with categories like perpetrators, victims (or survivors) and beneficiaries because they cause division, and it is not that easy to say who belongs where? How do I succeed in forgetting the past in a morally acceptable way?

Others ask how to define our social identities in terms of the vision and ideal of a new society rather than in terms of the notions of apartheid and even post-apartheid. All 'post' words indeed betray something of the old to which they refer:

Why do we keep on defining ourselves in terms of apartheid? Can't we define ourselves in terms of the vision of a new society, the same vision that the struggle against apartheid adhered to and that was documented in the Freedom Charter ${ }^{1}$ and at the launch of the United Democratic Front ${ }^{2}$, and that is now to a high extent articulated in the Bill of Rights of the South African Constitution? Does the language of shame and guilt, pain and anger not betray a negative theological anthropology that expects nothing good from human beings? Does this discourse in fact not underestimate the forgiving, transformative and renewing power of the triune God?

Some questions deal with feelings of shame and guilt:

What is the relationship between confession of guilt, confession of faith and confession of hope? How do I get rid of the exhausting and pacifying uncertainty in me and the anxiety that I unwittingly might be doing something wrong against my brothers and sisters of other ethnic groups?

Some questions express the theme of accountability for wrongs that predecessors committed:

For how long do we have to say sorry for wrongs that we did not commit ourselves but that our fore-parents committed? Reparative measures are im- 
portant but for how long will affirmative action discriminate against so-called beneficiaries and bereave them of the opportunity to fully actualise their potentialities to the honour of God and for the sake of the wellbeing of others?

A few years ago a white student said he found it painful that he lives very comfortably whilst some of his classmates do not always have access to food. He struggled with the reality that he was born in a relatively affluent family, and asked with urgency how he personally, as a student benefiting from the material care of his parents, could address the immense inequalities of our society.

Some students employ a cognitive approach and ask what can be learned from other post-liberation contexts:

Would it not be helpful and illuminating and even energising for current debates about the wrongs of apartheid to broaden our focus and discuss other collective wrongs, eg the wrongs committed by the British against white Afrikaans people during the two wars of the late nineteenth and early twentieth centuries, and the collective wrongs of people against each other in other parts of Africa and the world?

A student from a disadvantaged community raised a question about the forgiveness of the wrongdoer:

Why do the wronged always have to forgive and pay the price for fixing problems caused by others? Is the Christian notion of forgiveness not bad news for the wronged? Does it not justify a form of sado-masochism, ie does it not legitimise the sadism of the perpetrator whilst it calls the wronged to a life of masochistic self-sacrifice and self-hate?

The questions of our MDiv classes are the questions of all South Africa. They may even reflect the questions of other pluralistic societies, and of societies who are moving from oppression and enmity to freedom and friendship. These questions continuously surface in our private and public discourses and are posed by an increasing number of people in various parts of the world. In our interaction with colleagues in the circle of the Global Network for Public Theology - of which I was the first chairperson - we become aware of the presence of these and related questions and struggles across the world.

In this chapter I suggest we pay attention to the notion of a pedagogy of hybridity as a category that may provide some guidelines for dealing with these unavoidable questions. I briefly analyse the meaning of the notion of hybridity in contemporary social scientific discourse before discussing some features of a pedagogy of hybridity. I conclude the chapter by demonstrating 
that a pedagogy of hybridity has the potential to enhance the quest for thicker forms of reconciliation and justice: namely, just reconciliation and reconciling justice. This discussion will illuminate the description and use of the notion of hybridity. Furthermore, the discussion of hybridity, features of hybridity and thicker forms of reconciliation and justice may provide guidelines for addressing the questions of our students and of people in South Africa and other parts of the world.

Where we succeed in naming and addressing these questions constructively, and where we help to equip students to deal with them constructively, we may make significant contributions to the building of the common good in South Africa. This is especially true since the common good is not a value neutral notion. It has a bias towards interdependence, reconciliation and justice, as reflected in this definition of the common good by Vatican 2 (Gaudium et spes - The Pastoral Constitution on the church in the modern world, 1965):

Every day, human interdependence grows more tightly drawn and spreads by degrees over the whole world. As a result, the common good, that is, the sum of those conditions of social life which allow social groups and their individual members relatively thorough and ready access to their own fulfilment, today takes on an increasingly universal complexion and consequently involves rights and duties with respect to the whole human race.

\section{Hybridity}

Hybridity is used in contemporary social scientific discourses in the contexts of post colonisation and globalisation. The word, which literally means mixture, has its origins in the contexts of different plant species and different racial groups. It refers, for instance, to the mixing of races. In modern race discourses these hybrid or mixed races were viewed as inferior.

A more positive use of the concept of hybridity has developed during the last few decades. Racial discourses increasingly reject the idea of a so-called pure race without any form of hybridity. In apartheid South Africa the controversial work of the historian Hans Heese (1984; repr 2005), which traced the roots of some extremist white apartheid ideologists to, amongst others, the Khoi-San indigenous groups, paved the way for a re-evaluation of the notion of hybridity.

The deployment of the notion of hybridity in social scientific discourse (Pieterse, 2004; Bhabha, 1994) is of particular interest. Hybridity challenges certainties and essentialisms. It resists monophony and promotes the idea of 
polyphony. It carries the notion of liminality, which refers to an in-between state where old, certain, clearly defined identities are re-negotiated and the door is opened for the new, imaginative and surprising. Hybridity acknowledges complexity and ambiguity.

I propose that we use the notion of hybridity heuristically and almost playfully. It might open new imaginative possibilities in our reflections on themes like unity, justice and reconciliation. I also propose that we use it rhetorically. It might help make Christian convictions accessible to contemporary cultural life and public discourses. In this sense the notion of hybridity acquires a public, theological, ethical and pedagogical function. In some ways I use the concept existentially. Although all races are hybrid in nature, I belong to an ethnic group, the 'coloured' group, which is described as the most hybrid one!

Hybridity, it seems to me, does not advance a type of mixing that dissolves the entities that mix, that brings forth a totally new uniformed entity. Hybridity does not destroy particularity. Rather, it refers to a mingling, exposure to the other, dialogue with the other, interaction with the other, participation in the life of the other, hospitality to the other, learning from the other. This exposure does not leave one unchanged. One has internalised something of the other.

As this interaction and communing with the other, as this exposure to and participation in the life of the other, as this life of porous boundaries and vulnerable openness to the other, as life on the thresholds and margins, as life in liminal and uncertain in-between spaces, as life of openness to many voices and many lenses - in each of these guises hybridity impacts positively on the way we define our humanness.

Hybridity helps us journey from minimalist to maximalist descriptions of ourselves and others, from mono-descriptions to multi-descriptions, from exclusive descriptions to inclusive descriptions, and hopefully, therefore, from unjust to just descriptions, from dehumanising to humanising descriptions.

This entails that I am a heterosexual person, but through my participation in the life of gays and lesbians I also wear the lenses of my gay and lesbian brothers and sisters. I am heterosexual but I am also more than that. I am a male, but because of my interaction with females I also wear the earphones of women and try to hear what they hear. I am male, but I am also more than male.

I am coloured, brown, Khoi, Griqua, Hessequa, Outeniqua or any category used to describe these brown groups in South Africa, but I am also more than 
that. My life in South Africa which I shared with my Xhosa, white and Indian brothers and sisters did not leave me unchanged. I also live with their lenses. I am more than coloured.

A pedagogy of hybridity might enable me to wear the lenses and earphones of other nationalities, ages and socio-economic groups, as well as the lenses and earphones of people living with disabilities, and even of nature, including animals, plants and the rest of our natural environment.

So, a lifestyle and pedagogy of hybridity might assist us in overcoming the alienations and injustices that are expressed in homophobia and misogyny, racism and xenophobia, ageism and classism, handicappism and ecocide.

The pedagogy of hybridity paves the way for Christian denominations to live in a unity and catholicity that comes to expression in ecumenicity through particularity. The maximalist denominationalism which makes me say I am more than Uniting Reformed or Dutch Reformed or Presbyterian or Anglican might contribute to our liberation from divisive denominationalism.

This pedagogy of hybridity should help us move to higher levels of peace among the religions of the world. The relatively high level of peace among people from different religions in South Africa might be attributable to the hybridic interaction, collaboration, and life together of these people in our neighbourhoods and communities. I am Christian, but through my interaction with my brothers and sisters from other religions, I know I am more than that.

\section{Features of a pedagogy of hybridity}

If the following features of a pedagogy of hybridity guide and drive us, we may deal more constructively and faithfully with the challenges of reconciliation and justice on our campuses and in our societies. I posit at least seven features of a pedagogy of hybridity in service of reconciliation and justice.

\section{Plurality}

Discussions in our MDiv class illuminate the plurality of voices, opinions and perspectives on challenges like reconciliation and justice. These voices are manifold and more often than not, contradictory. A pedagogy of hybridity accepts this plurality and deals with it constructively by exposing views to each other, through dialogue and the search for consensus, or allowing peaceful coexistence and continuous deliberations in the case of incommensurable positions. 
Let us take the challenge of homosexuality as an example. An American theologian, William Stacey Johnson (2006), has identified seven positions among Christians in all parts of the world regarding the ordination for ministry and the confirmation in marriage of gay and lesbian people. This plurality of positions has been reflected in our classes over the years. Just as no major church in the world could reach consensus on this challenge, the opinions in our classes are divided. We are in agreement in rejecting all forms of homophobia, both crude and subtle. We guide students to practise hybridity, to wear the lenses of others. This can enable them to listen and understand the person of a different sexual orientation, and therefore to tolerate and embrace the other, although they may differ with regard to specific decisions. We encourage them to practise tolerance and embrace those of a different sexual orientation and we encourage them to build communities of tolerance where opposing views on this and other matters can enjoy hospitality and peaceful co-existence.

\section{Ambiguity}

Ambiguity refers to the fact that the same phenomenon or reality can be described in different and even contradictory ways by different people and in different contexts. Ambiguity also refers to the shifting meanings of words, sentences and concepts (Tracy, 1984; repr 1994). We often wrongly associate ambiguity with unclarity and vagueness, and want to avoid it more often than not (Levine, 1985).

People who cannot live with ambiguity either choose absolutism or relativism. Absolutism implies that only my interpretation, description and solution is right. Absolutism paves the way for judgementalism, fundamentalism and even some forms of anti-intellectualism or irrationality, as well as the stereotyping, stigmatisation, demonisation and annihilation of the other. Relativism feeds an attitude of passivity, melancholy, pessimism, internal emigration and nihilism.

In our reconciliation and justice discourses absolutism or relativism are the more popular options. Many people cannot bear the vulnerability of uncertainty and prefer absolutist and fundamentalist positions with all their negative implications. Others do not show the commitment of making a responsible choice and bearing the consequences of that choice. So, whilst thinking that they stay neutral by adhering to relativism, they do in fact make a choice. They make a bad choice, the choice of being unwilling to make a stand for what is wise, right and good. 
Travelling the road of ambiguity asks for wisdom, courage and patience. It also demands the ability to communicate highly sophisticated positions in clear and intellectually accessible ways.

\section{Complexity}

Students in our class also plead that we investigate the lessons South Africans can learn from the quests for reconciliation, justice and transformation in other post-liberation contexts like, amongst others, the post-South African War period, the post-Second World War period in Germany or the post-civil rights struggle in the United States. This broader focus renders the issues more complex and sheds additional light on our own struggle. Thorough historical analyses and cross-national analyses of our own and other quests for reconciliation and justice help us describe our own challenges in a more nuanced way. It also helps us gain strength and hope from others' struggle to actualise the common good, the good society of unity and reconciliation, justice and peace. Moreover, it helps develop the right emotional orientation and sensitivity for our local challenges. These analyses of other contexts also free us from over-sensitivity and insensitivity, both of which are stumbling blocks on the road to peace.

\section{Duality}

To address the challenging questions regarding reconciliation and justice we also need to live with duality. By this I mean the capacity to live with the notion of both 'and' and the more popular 'either ... or'. We need to say yes to more than one thing at once, even though it may seem that these things contradict each other.

Let's take the question of whether we should talk about the past as an example. Should we still continue to talk about the past? Yes, because if we do not talk about the past, the anger, pain, shame and guilt we have not dealt with will keep on haunting us. Should we stop talking about the past? Yes, because if we do not stop talking about the past, we may keep each other trapped in the past and foreclose the wonderful prospect of journeying together and energetically into the future.

Or take another question: Do we need to refer to each other in colour categories? Yes, we need to do this for the sake of trying to repair the wrongs that were committed along colour lines for centuries, on the condition that this is a fairly applied and interim arrangement and as long as we also address other categories of injustice like those pertaining to gender, class, disability, age and the environment. Do we need to stop referring to each other in colour cate- 
gories? Yes, we need to avoid racial categorisation for the sake of working together to actualise the vision of societies where the importance of race ceases. A pedagogy of hybridity teaches us to live simultaneously with more than one yes to contradictory questions.

\section{Paradox}

Church reformers like Martin Luther posited the paradoxical nature of human anthropology. We are simultaneously sinners and justified ones. This paradox, this apparent but not real contradiction, permeates human existence. Faithful servants of reconciliation and justice learn to live with the tension of paradox. A few years ago the first coloured rector of the Free State University, Jonathan Jansen, told an audience about his positive experiences at a rugby test match between South Africa and New Zealand in Bloemfontein. A Sotho person sang traditional Afrikaans folksongs. The mainly white spectators loudly supported the brilliant black Springbok prop forward. Earlier at a soccer match that he had attended, the main hero of the mainly black spectators was a white player from the South African national soccer team.

After reading this I watched a rugby test a week later at the reunion function of my Stellenbosch University residence, Huis Visser, where I was warden. A few hundred former residents of Huis Visser watched the match in a tent on a big screen. They jointly sang South Africa's national anthem. They sang the non-Afrikaans part just as loud and enthusiastically as the Afrikaans part. They knew all the non-Afrikaans words. I was energised. To think that these men, some of whom were in their eighties, sang the new anthem of a new society on the same grounds where they sang the anthem of apartheid South Africa for many decades. One of them even shouted: 'we should have recorded this on video!'

With these experiences of hope in my mind and heart I attended the celebration of a friend's fiftieth birthday later that evening. While we stood in line for food one of the guests told me that he could not support the Springbok rugby team. He explained that at the test match in Bloemfontein - the one that filled Jansen and me with hope for reconciliation and justice - a few white supporters insulted coloured supporters who were wearing Springbok support jerseys, accusing them of wearing jerseys that actually belong to white people.

The same rugby matches in the same country were experienced by South Africans in conflicting ways. To serve reconciliation and justice we need to hold on to each of these sets of experiences, the positive ones as well as the 
negative. We cannot absolutise only one of the two. We need to say yes, good things happen in South Africa - otherwise we will be dishonest and will become discouraged, melancholic and apathetic, and unfaithful to our godgiven calling. But we also need to say yes, bad things happen in South Africa - otherwise we will be dishonest and become unrealistic and naive, insensitive to the pain and anger in our society. With this sense of paradox we need to live.

\section{Proximity}

A pedagogy of hybridity, of interacting and communing with the other, also advances the notion of proximity amongst people. The logic of the three articles of the Belhar Confession, a confessional document that was adopted in 1986 by the former Dutch Reformed Mission Church, today known as the Uniting Reformed Church in Southern Africa after its merger with the major part of the Dutch Reformed Church in Africa, is that visible, concrete, experienced unity, where people develop sympathy, empathy, interpathy and solidarity (article 1), stands in service of reconciliation (article 2) and justice (article 3).

US theologian David Augsberger (1989:31) provides a helpful definition of sympathy, empathy and interpathy:

Sympathy is a spontaneous affective reaction to another's feelings experienced on the basis of perceived similarity between observer and observed. Empathy is an intentional affective response to another's feelings experienced on the basis of perceived differences between the observer and observed. Interpathy is an intentional cognitive and affective envisioning of another's thoughts and feelings from another culture, worldview and epistemology.

Reconciliation and justice grow where people do not live outside of hearing distance of one another (Esterhuyse, 1989) but where we hear each other, see each other, feel each other, participate and share in each other's lives, in our joys and sorrows, in our guilt and shame, in our anger and pain. And this proximity need not and cannot be physical all the time. The electronic media and other forms of communication, as well as art, literature, culture and sport, can be used to create spaces of proximity amongst a plurality of people.

\section{Absurdity}

The last feature of a pedagogy of hybridity relates to a logic that seems to be absurd, ridiculous and foolish. For reconciliation and justice to materialise, we need forgiveness. Forgiveness opens the door to recognition of guilt, con- 
trition and remorse, confession of guilt in the face of overwhelming, forgiving love, confession of faith which accepts forgiveness and confession of hope which says 'yes' to a new life of sanctification and restitution. In the light of this logic, Archbishop emeritus Desmond Tutu (1999) calls his famous book No Future without Forgiveness (also cf. Smit, 1996; repr 2007).

South Africans are continually surprised by private and public experiences of this absurd love, this forgiving love. This love embodied in the life and person of Nelson Mandela. This absurd, forgiving love was experienced at the hearings of the Truth and Reconciliation Commission. Manifestations of this love granted South Africa the wonder of a transition to democracy without civil war. The sustainability of our peace is dependent upon our commitment not to make this forgiveness cheap. We live with the hope and expectation that the wonder of a love that forgives will open the gates to a responding love that repents and repairs, a love that heals the brokenness and that rights the wrongs.

\section{Just reconciliation and reconciliatory justice}

A pedagogy of hybridity eventually paves the way for the actualisation of socalled thicker manifestations of reconciliation and justice: the idea which is derived from, amongst others, the Judaeo-Christian tradition, that reconciliation cannot be discussed without justice and that justice cannot be discussed without attention to reconciliation. This is a crucial notion in educational and social contexts where we so often hear views which separate the reconciliation and justice discourses from each other.

In biblical thinking reconciliation has two dimensions. Reconciliation (Greek: hilasmos) has to do with the expiation of wrongs and stumbling blocks to atonement (at-one-ment).

Reconciliation (Greek: katalassoo) refers to harmony in the relationship with the other. This reconciliation has in mind the embrace that US theologian Miroslav Volf (1996:171) refers to: the embrace of different races, tribes, nationalities, socio-economic groups, genders, sexual orientations, age groups, 'normal' and disabled people. This reconciliation pleads for the removal of stumbling-blocks in the way of peaceful living, in the way of the embrace. Reconciliation therefore implies opposition to injustices like violence, war, racism, tribalism, xenophobia, classism, misogyny, homophobia, ageism, disablism and ecocide.

Reconciliation aims at embrace through the expiation of wrongs and stumbling blocks to that embrace. The connectedness of reconciliation and justice 
is thereby revealed. The justice that is confessed in both the Old and New Testament is rightly described as compassionate justice. In line with the biblical use of these concepts, both the sacrificial (Hebrew: tsedaqah) and forensic (Hebrew: mishpat) dimensions of justice are referred to. For New Zealand theologian Christopher Marshall (2001:59) justification by faith is an expression of restorative justice.

The notion of sacrifice has another aspect: justice cannot be reached unless there is the willingness to sacrifice for the sake of the other. Moreover, justice does not seek revenge, but it is merciful. It seeks the healing and restoration of both perpetrators and victims. In fact it seeks the healing of all broken relationships. Therefore this justice is called restorative justice.

Marshall's analysis of the use of justice in the New Testament enables him to refer to justice as restorative or covenantal justice (2001:35-93). Covenantal justice goes beyond retribution and punishment and seeks, like reconciliation, the healing of relationships. Like reconciliation, restorative and covenantal justice seeks embrace. It seeks the renewal of the covenant between God and humans, between humans themselves and between humans and the rest of creation, from the most local to the most global levels.

This brief outline demonstrates the close resemblance between justice and reconciliation. Although the two concepts are not identical, it is clear that, when we view justice as compassionate, covenantal and restorative - justice that seeks reparation and restitution through forensic means, and justice that seeks, in a merciful way and in the willingness to sacrifice, the healing and renewal of relationships - justice and reconciliation are both at the service of the dawning of embrace or, in the words of US theologian Nicholas Wolterstorff (1983:70), the dawning of 'shalom' or peace.

Where our students and citizens develop a pedagogy of hybridity, of exposure to each other, of wearing each others' lenses, we make progress towards the thicker forms of reconciliation and justice, to just reconciliation and reconciliatory justice. Shouting at each other across the distances of distrust and alienation closes the door to just reconciliation, and merely seeks cheap reconciliation without justice. Shouting at each other across the distances of pain and anger does not serve lasting reconciling justice, but brings about alienating and destructive justice that cannot last because it forms seedbeds for new forms of injustice. 


\section{Conclusion}

The pedagogy of hybridity is a pedagogy of hope. It has relevance not only for classes dealing directly with the theme of inclusion, justice and reconciliation. It may have healing implications and relevance for all of campus life, including the spheres of academic work, academic support, academic residences, social life, cultural life, sport, free time, amongst others. The pedagogy of hybridity may bring hope to broader societies in South Africa and elsewhere in their struggles against exclusion, enmity and injustice. The broader societal impact of our pedagogies is crucial for campuses in contemporary societies across the globe, which are all characterised by plurality and complexity and which struggle to journey away from a divided and oppressive past to a united and liberating future.

\section{Notes}

1 Charter of core freedoms drafted by the Congress movement in Kliptown in South Africa in 1995.

2 The United Democratic Front was a popular non-racial organisation that fought apartheid inside South Africa in the 1980s and 1990s.

\section{References}

Augsberger, D (1989) Pastoral Counselling across Cultures. Louisville: Westminster/John Knox Press

Bhabha, Homi K (1994) The Location of Culture. London: Routledge

Esterhuyse, W (1989) Broers Buite Hoorafstand: skeiding van die kerklike weë. Kaapstad: Tafelberg Gaudium et spes The Pastoral Constitution on the church in the modern world (1965)

Heese, H F 1984/repr (2005) Groep Sonder Grense: die rol en grense van die gemengde bevolking van die Kaap, 1652-1795. Pretoria: Protea Boekhuis

Johnson, W S (2006) A Time to Embrace. Same-gender relations in religion, law, and politics. Grand Rapids: Eerdmans

Levine, D (1985) The Flight from Ambiguity: essays in social and cultural theory. Chicago: Chicago University Press

Marshall, C (2001) Beyond Retribution. A New Testament vision for justice, crime and punishment. Grand Rapids: Eerdmans

Pieterse, J (2004) Globalization and Culture: global mélange. Oxford: Rowman and Littlefield

Smit, D J (2007) Confession - guilt - truth - and forgiveness in the Christian tradition. In E Conradie (ed) Essays in Public Theology. Stellenbosch: Sun Press

Tracy, D 1984/repr (1994) Plurality and Ambiguity: hermeneutics, religion, hope. Chicago: Chicago University Press

Tutu, D (1999) No Future without Forgiveness. London: Rider

Volf, M (1996) Exclusion and Embrace. A theological exploration of identity, otherness and reconciliation. Nashville: Abingdon Press

Wolterstorff, N (1983) Until Justice and Peace Embrace. Grand Rapids: Eerdmans

Young, R (1995) Colonial Desire: hybridity in theory, culture and race. London: Routledge 